\title{
The Health Belief Model and Preventive Measures: A Study of the Ministry of Health Campaign on Coronavirus in Saudi Arabia
}

\author{
Saud A. Alsulaiman (D) and Terry Lynn Rentner
}

School of Media and Communication, Bowling Green

State University, Bowling Green, Ohio, USA

\begin{abstract}
As of August 2017, approximately 684 people have died in the Kingdom of Saudi Arabia since the coronavirus Middle East respiratory syndrome (MERS-CoV) outbreak in 2012. Saudi Arabia became the leading country for the number of illnesses and deaths related to MERS-CoV, making this a health megacrisis. Early Ministry of Health $(\mathrm{MOH})$ communication efforts proved ineffective and created anger, confusion, and mistrust. Changes in command, implementation of new guidelines and policies, and a health preventive campaign have been instrumental in the fight. The $\mathrm{MOH}$ launched the "We Can Stop It" campaign in 2015. This study shares results from a survey of 875 students from King Saud University on the credibility of $\mathrm{MOH}$ information and effectiveness of the campaign's prevention recommendations. Results show that the $\mathrm{MOH}$ is a credible source of information and that Saudis are following most, but not all, recommended preventive measures. Those persons with higher perceived benefits and lower barriers are more likely to follow recommended guidelines.
\end{abstract}

KEYWORDS: Coronavirus; MERS-CoV; Ministry of Health of the Kingdom of Saudi Arabia; health belief model; health campaigns

Beginning in September 2012, a major health crisis in the Kingdom of Saudi Arabia (KSA) erupted. The coronavirus Middle East respiratory syndrome (MERS-CoV), a serious and sometimes fatal infection, had infected more than 1,668 people by August 3, 2017, and taken the lives of 684 people in the KSA (Ministry of Health of the Kingdom of Saudi Arabia $[\mathrm{MOH}], 2017)$. These numbers ranked the KSA as the country with the highest number of cases in the world, prompting the Ministry

CONTACT Saud A. Alsulaiman·E-mail: sauda@bgsu.edu • 306 Kuhlin Center, Bowling Green State University, Bowling Green, $\mathrm{OH} 43403$ 
of Health of the KSA (MOH) to take action (Centers for Disease Control and Prevention [CDC], 2015, 2017; MOH, 2017). The problem is that initial responses from the $\mathrm{MOH}$ left KSA residents confused, angry, and suspicious of the MOH's mixed messages. Saudis were first told by minister of health Abdullah al Rebeeah that he had no idea why the disease was spreading across the KSA, but instead of offering precautionary measures, he said that no clinical measures were needed (Alomran, Knickmeyer, \& McKay, 2014). This created a megacrisis for the KSA, which faced a significant threat to the health of its people without knowing why or how to stop the virus from spreading.

A megacrisis is defined as "a set of interacting crises that are severe in impact, complex in nature, and global in fallout, with no seeming end in sight" (Yen \& Salmon, 2017, p. 1). The impact of MERS-CoV on not only the KSA but also the world defined MERS-CoV as a megacrisis. The World Health Organization (WHO; 2016) has stated that other countries, such as South Korea, are in states of high alert, with fears that the outbreak could cause severe harm to health and the economic and social services of countries where health systems continue to be unprepared. Furthermore, the WHO (2016) warned that hospital outbreaks of MERS-CoV in the KSA "could escalate both nationally and internationally into a perpetual global health threat" (para. 1). The number of deaths, the absence of vaccines to treat the disease, and the complexity of the disease and how it transmits further qualify MERS$\mathrm{CoV}$ as a megacrisis.

It took the firing of Abdullah al Rebeeah and the hiring of a new minister of health before the $\mathrm{MOH}$ launched a comprehensive campaign on March 4, 2015, called "We Can Stop It," on its website. The goals of the campaign were to educate the public about MERS-CoV and to inform them about prevention best practices ( $\mathrm{MOH}, 2015)$. The campaign incorporated both traditional and social media that included key messages and specific preventive actions. This may indicate that people started to gain trust in the information the $\mathrm{MOH}$ disseminated after its initial response to the MERS-CoV crisis. Nonetheless, the extent to which this campaign has been effective in terms of education and prevention, and in improving the MOH's credibility, is unknown.

The purpose of this study is to assess the extent to which KSA residents are adhering to the preventive measures promoted by the MOH's 
"We Can Stop It" campaign. Using the health belief model (HBM), we surveyed students from King Saud University (KSU) to assess the credibility of the MOH's messages. We then analyzed the perceived susceptibility and perceived severity of contracting the disease along with the perceived benefits of and perceived barriers to following the MOH's prevention recommendations. We further analyzed the extent to which the campaign messages impacted cues to action and self-efficacy to perform the recommended preventive behaviors.

\section{Case Study}

The MOH was established in 1951 and charged with carrying out health affairs in the kingdom, including all regulations, laws, and legislation for all governmental and private health sectors in the KSA. It monitors and regulates health institutions' performance and offers training to all health practitioners. Approximately $6 \%-7 \%$ of the country's budget is allotted annually to the $\mathrm{MOH}$ to develop and enhance health services $(\mathrm{MOH}, 2017)$. Much of the money is spent on awareness and education campaigns, using multiple communication channels that include traditional media and, more recently, social media.

The first case of MERS-CoV was documented in the KSA in September 2012. The WHO (2015) defined MERS as a "viral respiratory disease caused by novel MERS-CoV" (para. 1). Its symptoms include severe acute respiratory illness, with fever, cough, shortness of breath, congestion in the nose or throat, and possible diarrhea (CDC, 2015; $\mathrm{MOH}, 2017$ ). The virus circulated mainly in countries inside the Arabian Peninsula, such as the KSA, the United Arab Emirates, Kuwait, and Qatar, as well as in some Middle Eastern countries, such as Turkey and Egypt (WHO, 2015a). Although the majority of cases of MERS$\mathrm{CoV}$ are attributed to human-human infections, camels are believed to play a significant role in transmitting the disease among human beings. However, researchers have not yet determined the exact role and route of the transmission (WHO, 2015b).

\section{Initial Crisis Response}

When the outbreak of MERS-CoV first hit the KSA, the MOH did a poor job of providing clear and updated information. For example, 
during a news conference, Minister al Rabeeah told the public that he had no idea why MERS was spreading across the KSA and said that no clinical measures were needed during pilgrim season, a time during which the KSA hosts millions of people every year from all around the world (Alomran et al., 2014). The MOH provided no guidelines, leaving people and health care providers panicked, confused, and angered (British Broadcasting Corporation, 2014). There was also no precrisis planning, meaning that the $\mathrm{MOH}$ had to start from scratch in understanding the virus and how to communicate preventive measures to the public. Saudi physicians and some international virologists from research centers echoed the public outcry, stating that poor communication and lack of accountability have hindered the KSA's ability to handle such crises (Reuters, 2014). Poor communication from the $\mathrm{MOH}$ trickled down to other health entities, intensifying the problem and creating a lack of communication and mismanagement between hospitals, government departments, and laboratories. This caused delays in reporting and recording MERS-CoV cases, according to some Saudi physicians (Reuters, 2014). As a result, Minister al Rabeeah was fired from his position. Two other ministers were hired and fired within a short period of time. It was not until 2014, two years after the initial outbreak, that people witnessed dramatic changes in how the $\mathrm{MOH}$ communicated with the public. This provided new hope for change and improvement in the MOH's policies concerning how it handles crisis responses (Reuters, 2014).

\section{New Efforts, New Hope}

The $\mathrm{MOH}$ took significant steps to reduce the spread of MERS-CoV by implementing new communication strategies and prevention guidelines. The $\mathrm{MOH}$ stated that it "put in place measures to ensure best practices of data gathering, reporting (and) transparency are strictly observed" and "to ensure that from now on, case information will be accurate, reliable and timely" (Reuters, 2014, para. 5). In an effort to regain the public's trust, the $\mathrm{MOH}$ established a Command and Control Center (CCC) in June 2014 consisting of physicians, scientists, and experts in partnership with international organizations, such as the WHO. The CCC's role is to conduct research, control infection, 
manage clinical operations, and conduct data analysis with regard to MERS-CoV (MOH, 2017; Reuters, 2014). As a result, the $\mathrm{MOH}$ started to establish two-way communication by releasing more accurate and timely information to the public through multiple communication channels, including social media in different languages.

On March 4, 2015, the MOH launched its most aggressive and comprehensive MERS-CoV campaign, called "We Can Stop It." The aim of this campaign was to increase awareness about MERS-CoV and inform the Saudi people about best practices to prevent the spread of MERS-CoV disease ( $\mathrm{MOH}, 2015)$. Traditional media, including radio, television, and newspapers, and social media are being used to reach various audience segments. Preventive messages are being conveyed through posters, brochures, and interviews with health experts. Key messages include (a) information on how the virus is transmitted, (b) signs and symptoms, and (c) what to do if one feels sick. Additional resources are also provided.

The campaign has disseminated short videos via social media to deliver preventive and instructional health messages to encourage individuals to wash their hands with soap for at least 20 seconds, follow a healthy diet to boost the immune system, exercise, avoid camels, and wear masks as well as instructing them how to sneeze to avoid the spread of germs. Table 1 provides examples of key executional and preventive messages distributed via multiple communication channels.

The use of Twitter has been instrumental in increasing awareness and knowledge of the disease while offering preventive measures. People are asked to link their Twitter accounts to the "We Can Stop It" campaign to receive and retweet weekly updated health messages from the $\mathrm{MOH}$. The number of participants on Twitter has reached more than $8,480,718(\mathrm{MOH}, 2017)$.

The developers of this campaign further recognized the importance of audience segmentation, a key ingredient to a successful campaign that was missing from earlier efforts. Campaign messages were developed specifically for high-risk groups: (a) parents and teachers, (b) patients and their families, (c) health care professionals, (d) camel herders, and (e) those in the workforce $(\mathrm{MOH}, 2017)$. Although the frequency of coming into contact with a camel depends on individual lifestyle, 
TABLE 1 Key Preventive Messages Described in the Campaign Materials

\begin{tabular}{|c|c|c|}
\hline Channel & Type of message & Message \\
\hline $\begin{array}{l}\text { Posters distributed in hospitals, } \\
\text { workplace, schools, and } \\
\text { shopping malls }\end{array}$ & $\begin{array}{l}\text { Educational and } \\
\text { preventive }\end{array}$ & $\begin{array}{l}\text { Definition of MERS-CoV, how } \\
\text { it transmits, and its symptoms; } \\
\text { poster also includes the MERS- } \\
\text { CoV preventive measures, such as } \\
\text { wearing a mask and using a tissue } \\
\text { when coughing and sneezing }\end{array}$ \\
\hline $\begin{array}{l}\text { Videos distributed via the } \\
\text { MOH's YouTube channel and } \\
\text { social media, such as Twitter } \\
\text { and Facebook }\end{array}$ & Preventive & $\begin{array}{l}\text { How to avoid MERS-CoV through } \\
\text { adopting health behaviors like } \\
\text { frequent handwashing }\end{array}$ \\
\hline $\begin{array}{l}\text { Videos distributed via the } \\
\text { MOH's YouTube channel and } \\
\text { social media platforms }\end{array}$ & Preventive & $\begin{array}{l}\text { What to do if a person develops } \\
\text { MERS-CoV symptoms }\end{array}$ \\
\hline $\begin{array}{l}\text { Videos mainly circulated via } \\
\text { the MOH's Twitter, Facebook, } \\
\text { and YouTube accounts by } \\
\text { including \#MERS-CoV }\end{array}$ & Educational & $\begin{array}{l}\text { The proper way of wearing and } \\
\text { using masks }\end{array}$ \\
\hline $\begin{array}{l}\text { Videos mainly circulated via } \\
\text { the MOH's Twitter, Facebook, } \\
\text { and YouTube accounts by } \\
\text { including \#MERS-CoV }\end{array}$ & Educational & $\begin{array}{l}\text { Important guidelines outlining } \\
\text { how to handle camels and avoid } \\
\text { those infected with MERS-CoV }\end{array}$ \\
\hline $\begin{array}{l}\text { Twitter: People were } \\
\text { encouraged to participate } \\
\text { in a campaign in Twitter by } \\
\text { registering their accounts with } \\
\text { the } \mathrm{MOH} \text {. The } \mathrm{MOH} \text { would } \\
\text { tweet about MERS-CoV weekly } \\
\text { on behalf of each registered } \\
\text { account. }\end{array}$ & $\begin{array}{l}\text { Educational and } \\
\text { preventive }\end{array}$ & $\begin{array}{l}\text { All information related to MERS- } \\
\text { CoV and healthy behaviors }\end{array}$ \\
\hline TV & $\begin{array}{l}\text { Educational, } \\
\text { preventive, Q\&A }\end{array}$ & $\begin{array}{l}\text { All information related to MERS- } \\
\text { CoV and healthy behaviors } \\
\text { discussed with health experts and } \\
\text { officials from } \mathrm{MOH} \text { and different } \\
\text { hospitals }\end{array}$ \\
\hline Radio & $\begin{array}{l}\text { Updates and } \\
\text { reports }\end{array}$ & $\begin{array}{l}\text { What the } \mathrm{MOH} \text { is doing to reduce } \\
\text { MERS-CoV }\end{array}$ \\
\hline
\end{tabular}


campaign messages address this audience because Riyadh and Jeddah have the largest camel trades in the country.

\section{Literature Review on Health Belief Model}

The HBM was developed in the 1950 s with the aim of explaining and predicting individuals' health behaviors (Champion \& Skinner, 2008; National Cancer Institute, 2005). The HBM is a psychological model developed by psychologists Hochbaum, Rosenstock, and Kegels (1952/2016), who worked for the U.S. Public Health Service (Glanz, Rimer, \& Lewis, 2002; Janz \& Becker, 1984), and was first used to gain a better understanding of why free tuberculosis (TB) health screening programs were not very successful (Glanz et al., 2002; Hochbaum, 1958; Janz \& Becker, 1984). Particularly, the HBM aims to aid understanding of why individuals do not adopt disease strategies and behaviors during health campaigns and refuse to engage in preventive behaviors (Hayden, 2013; Hochbaum, 1958; Janz \& Becker, 1984; Thweatt \& Query, 2005).

The HBM encompasses four dimensions: perceived susceptibility, perceived severity, perceived benefits, and perceived risks. Perceived susceptibility posits that the more an individual perceives the risk of a disease, the more likely he or she will be to engage in behaviors to decrease that risk (Glanz et al., 2002; Hayden, 2013; Hochbaum, 1958; Janz \& Becker, 1984). Perceived severity includes some evaluation of the consequences of an illness based on medical information and knowledge as well as some beliefs about the negative consequences of a certain behavior or disease that might occur for an individual (Hayden, 2013; Janz \& Becker, 1984). The third dimension, perceived benefits, suggests that individuals perceive the value and usefulness of adopting new behaviors in regard to minimizing the risk of an illness and will likely adopt new behaviors based on their perceptions of their benefits in reducing threats (Hayden, 2013; Janz \& Becker, 1984). The fourth dimension, perceived barriers, is the most powerful dimension of HBM (Janz \& Becker, 1984), in that individuals evaluate the obstacles and difficulties they might encounter when adopting a new behavior. This dimension, however, might result in individuals giving up on adopting a new behavior (Hayden, 2013; Janz \& Becker, 1984). 
Individuals usually evaluate the benefits and consequences of a new behavior before overcoming the old one (Hayden, 2013).

The HBM also suggests that besides the four perceptions, individuals' behaviors can be influenced by what is called a cue to action, which includes external and internal cues. External cues are events, people, mass media, health providers, and any external factor that can trigger people to change their behaviors (Hayden, 2013; Janz \& Becker, 1984). Internal cues include psychological cues, such as pain and symptoms, that trigger individuals to adopt a new behavior (Janz \& Becker, 1984). Moreover, Bandura integrated a self-efficacy dimension into the model in 1988 (Rosenstock, Strecher, \& Becker, 1988). This dimension is concerned about an individual's own ability and capability to make a change, such as adopting new, healthier behaviors. Studies found that individuals who believe in their ability to achieve, and skill in achieving, a certain goal are more likely to attain that goal (Hayden, 2013).

Recently, the HBM has been widely used in health education campaigns and programs (Glanz et al., 2002) and has shown significant success in encouraging individuals to take preventive measures and adopt new behaviors to address diverse health issues around the world (see, for a study of vaccines among hemodialysis patients, Adams, Hall, \& Fulghum, 2014; for a study of reducing hypertension among women by encouraging physical activity, Hoseini, Maleki, Moeini, \& Sharifirad, 2014; for a study of a nutrition program by increasing calcium intake among girls in high schools, Naghashpour, Shakerinejad, Lourizadeh, Hajinajaf, \& Jarvandi, 2014; and for a study of injury prevention among high school students, Cao, Chen, \& Wang, 2014). Compared to other models, the HBM expands to support and maintain health behavior change interventions (Champion \& Skinner, 2008). Additionally, the model has been applied to many health behaviors and in many campaigns, including in several Arab countries, such as Jordan, the KSA, and Egypt, and has shown significant results (see, for a study of breast cancer in Jordan, Mikhail \& Petro- Nustas, 2001; for a study of colorectal cancer screening in the KSA, Almadi et al., 2015; and for a study in the practice of self-examination for breast cancer among Saudi women, Abolfotouh et al., 2015).

The HBM is suitable for assessing the impact of the MOH's messages 
on the perceived susceptibility and perceived severity of contracting the disease and on the perceived benefits of and perceived barriers to following $\mathrm{MOH}$ preventive guidelines. The following three research questions (RQs) were derived from this review:

RQ1: To what extent is the $\mathrm{MOH}$ seen as a credible source of information on MERS-CoV?

RQ2: What is the impact of the "We Can Stop It" campaign on the perceived susceptibility and perceived severity of contracting the disease and on the perceived benefits of and perceived barriers to following $\mathrm{MOH}$ preventive guidelines?

RQ3: To what extent have the MOH's campaign messages impacted cues to action and self-efficacy?

\section{Method}

\section{The Campaign}

The "We Can Stop It" campaign includes components on how the disease is transmitted, signs and symptoms, and what to do if one feels ill. Additional tactics include awareness presentations in schools, shopping malls, and universities; established school guidelines to educate parents, teachers, and students on the proper ways to prevent MERS-CoV; presentations across the country by health experts; and social events to teach prevention of the disease. This study focuses specifically on key preventive messages described in the campaign materials. These include washing hands frequently, wearing a mask when visiting sick people, staying away from camels, getting enough sleep and exercise, eating a healthy diet, and covering the mouth when coughing and sneezing. Many of these prevention tactics are demonstrated on posters and in videos and are shared on the MOH's website and on social media.

\section{Institutional Review Board Approval}

This study was reviewed and approved prior to its implementation by the Institutional Review Board (IRB) of Bowling Green State University (BGSU), Bowling Green, Ohio. The study was also reviewed and approved prior to its implementation by the Deanship of Scientific 
Research at KSU, Riyadh. After obtaining approval from the IRB at BGSU and the Deanship of Scientific Research at KSU, the researcher contacted the Deanship of E-Transaction and Communication to disseminate the e-mail invitation with the survey link.

\section{Sample}

A convenience online sampling method was used among college students at KSU. KSU enrolls approximately 50,000 students. The city of Riyadh was selected because it is one of two major cities with the highest number of MERS-CoV cases in the KSA ( $\mathrm{MOH}$, 2015). The university hosts domestic students from regions across the country as well as international students.

Data were collected at the end of the spring semester and the beginning of summer 2016. An invitation to participate in an online survey designed through Qualtrics was sent to the Deanship of E-Transactions and Communications at $\mathrm{KSU}$, and from there, it was sent directly to the students by e-mail. Three reminders were sent. A total 875 students participated in the survey, with a completion rate of $63 \%(n=551)$. All data were analyzed using SPSS.

\section{Instrument}

The researchers used the HBM Scale (Champion, 1993) but modified the scale to make it applicable to this study by substituting MERS-CoV for breast cancer. For example, the original scale asked respondents to agree or disagree with the statement "It is extremely likely I will get breast cancer," while in this study, the item was modified to read "It is extremely likely I will get MERS-CoV." The questionnaire consisted of 43 items addressing the HBM's variables. Seven questions examined perceived severity, five questions perceived susceptibility, seven questions perceived barriers, seven questions perceived benefits, eight questions cues to action, and nine questions perceived self-efficacy. A 5-point Likert scale was used, ranging from 1 (strongly disagree) to 5 (strongly agree). Higher scores on the six scales mean greater perceived severity, perceived susceptibility, perceived barriers, perceived benefits, cues to action, and self-efficacy, respectively. Internal consistency of the original scale was measured using Cronbach's alpha reliability coefficients, 
which yielded results from .80 to .93 . The content validity of this scale was also tested by three well-known judges who were familiar with the HBM (Champion, 1993). The scale used in this study was tested for reliability and validity and showed similar results to Champion's scale (Table 1). The study also adapted Meyer's media credibility scale of five dimensions-believability, accuracy, trustworthiness, fairness, and completeness - to assess the credibility of coronavirus messages disseminated across different communication channels (Meyer, 1988). Meyer's scale shows high reliability and high validity (West, 1994).

Respondents who never sought MERS-CoV information were blocked from answering and assessing the credibility of communication channels (media credibility scale) as well as the likelihood of using different communication channels to seek MERS-CoV information; they were automatically diverted to demographic questions. The questionnaire also included the MOH's recommended measures to prevent MERS-CoV.

\section{Validity of HBM MERS-CoV scale}

Prior to IRB approval, the survey went through translation and validity processes. The English-language questionnaire was assessed for content and face validity by three experts from BGSU who were professors and experts in health communication. Changes were made based on the experts' recommendations. Additionally, the researcher sent the questionnaire to a doctor and an epidemiologist to ensure appropriateness of language used, comprehension, and correctness of terminology. Modifications were made based on all experts' recommendations and notes.

After the editing process, cognitive testing was conducted by giving the survey to three English speakers. Each English speaker was asked to review the clarity, easiness, and appropriateness of the survey language. Comments and problems led to some revisions to the language and format of the questionnaire. After ensuring the clarity of the language used in the instrument, two native Arabic speakers who studied in the United States and hold master's degrees translated the questionnaire into Arabic. The researcher verified the translation to ensure that the correctness of the translation reflected the study aim and scope. Finally, 
the translation of the questionnaire was reviewed and verified by a faculty member in the Department of Arabic at KSU who held a master's degree in linguistic studies from the United Kingdom. Modifications were made to several items on the Arabic questionnaire regarding word choice and grammar. The researcher then conducted a pilot study by asking five college students, both male and female, to take the Arabic and English questionnaires to ensure clarity of the language. Few items were adjusted based on students' comments. Participants in the study were allowed to choose the language of the study (Arabic or English).

Reliabilities of the HBM subscales in this study were analyzed using Cronbach's alpha. Results were similar to the original scales Champion (1993) obtained (Table 2).

\section{Results}

\section{Descriptive Statistics}

Of the 875 students who participated in the survey, $65 \%$ were women and $35 \%$ were men. Approximately $80 \%$ of the students were aged $18-24$ years, followed by $18 \%$ who were $25-34$ years old. Approximately $12 \%$ of respondents were first-year students, $17 \%$ were second-year students, $17 \%$ were third-year students, and $16 \%$ were fourth-year students. Approximately $12 \%$ were fifth- and sixth-year students. Graduate students accounted for approximately $26 \%$ of the respondents (Table 3 ).

TABLE 2 Health Belief Model Reliability

\begin{tabular}{lcc}
\hline \multicolumn{1}{c}{ Subscale } & Current data & Champion's data \\
\hline Susceptibility & .84 & .93 \\
Severity & .82 & .80 \\
Barriers & .71 & .88 \\
Benefits & .77 & .80 \\
Cues to action & .80 & .83 \\
Self-efficacy & .82 & .88 \\
\hline
\end{tabular}


TABLE 3 Characteristics of the Study Sample

\begin{tabular}{|c|c|c|}
\hline Sample characteristic & $N$ & $\%$ \\
\hline \multicolumn{3}{|l|}{ Age (years) } \\
\hline $18-24$ & 436 & 79.13 \\
\hline $25-34$ & 99 & 17.95 \\
\hline $35-44$ & 15 & 2.74 \\
\hline $45-54$ & 1 & 0.18 \\
\hline \multicolumn{3}{|l|}{ Education } \\
\hline First year in college & 64 & 11.62 \\
\hline Second year in college & 92 & 16.70 \\
\hline Third year in college & 95 & 17.24 \\
\hline Fourth year in college & 88 & 15.97 \\
\hline Fifth year in college & 45 & 8.17 \\
\hline Sixth year in college & 25 & 4.54 \\
\hline Graduate student & 142 & 25.77 \\
\hline \multicolumn{3}{|l|}{ Gender } \\
\hline Female & 359 & 65.15 \\
\hline Male & 192 & 34.85 \\
\hline \multicolumn{3}{|l|}{ Field of study } \\
\hline Health or related major & 163 & 29.58 \\
\hline Agriculture or related major & 8 & 1.45 \\
\hline
\end{tabular}

\section{Research Question 1}

Participants in the study were first asked questions related to information seeking regarding MERS-CoV. These questions asked participants how often they sought information about MERS-CoV, where they first sought this information, and their likelihood of using various communication channels when seeking information. The study found that approximately $52 \%$ of participants sought MERS-CoV information one to two times a year, $23 \%$ sought it once every other month, $10.3 \%$ 
sought it once every month, $10 \%$ sought it one to two times per month, $5 \%$ sought it one to two times a week, and less than $1 \%$ sought MERS$\mathrm{CoV}$ information daily.

Approximately $87 \%$ said they would first go to the Internet. Approximately $72 \%$ of Saudis say they are very likely or likely to seek information about MERS-CoV from their doctors. The MOH Twitter site and website ranked as the third and fourth most highly chosen communication channels for seeking information, with $70 \%$ and $65 \%$, respectively. Interestingly, traditional media outlets did not rank highly as information-seeking channels, with $40 \%$ citing TV, $17 \%$ citing radio, and $13 \%$ citing newspapers as their likely or very likely sources for seeking information about MERS-CoV.

Participants were asked to what extent the crisis information obtained about MERS-CoV from each medium is believable, accurate, trustworthy, unbiased, and complete (Meyer, 1988). A 5-point Likert scale ranging from 1 (not accurate at all) to 5 (very accurate) was used for all five dimensions. Higher scores in the five dimensions mean greater believability, accuracy, trustworthiness, unbiasedness, and completeness. Participants were given 16 communication channels, such as the $\mathrm{WHO}$, the CDC, family and friends, and doctors or health providers, to rate credibility in regard to MERS-CoV information. The study showed that the MOH's website rates as the most believable $(M=4.56$, $S D=0.76)$, the most accurate $(M=4.44, M=0.78)$, the most trustworthy $(M=4.45, S D=0.80)$, and the most complete source $(M=4.13$, $S D=1.00)$, and it rated highly for being unbiased $(M=3.51, S D=$ 1.26). The MOH's Twitter account was ranked second after its website in regard to believability $(M=4.46, S D=0.83)$, accuracy $(M=4.30$, $S D=0.89)$, and trustworthiness $(M=4.37, S D=0.85)$ and rated highly for being unbiased and for being complete. The MOH's YouTube channel had strong scores on believability $(M=4.30, S D=0.90)$, accuracy $(M=4.17, S D=0.92)$, and trustworthiness $(M=4.24, S D=0.91)$ but lower scores on completeness $(M=3.85, S D=1.07)$ and being unbiased $(M=3.45, S D=1.18)$. The MOH's Facebook page was not seen to be as accurate $(M=3.97, S D=1.00)$ or as trustworthy $(M=4.01, S D=1.02)$ as its website or Twitter site.

Therefore, when combining the media credibility subscale, the 
TABLE 4 Subscale Correlations

\begin{tabular}{lccc}
\hline \multicolumn{1}{c}{ Subscale } & Spearman rho & SD & $\boldsymbol{M}$ \\
\hline Susceptibility & 0.078 & 0.74 & 2.25 \\
Severity & $0.085^{*}$ & 0.77 & 2.59 \\
Benefits & 0.075 & 0.61 & 3.78 \\
Barriers & $-0.271^{* *}$ & 0.69 & 2.43 \\
\hline
\end{tabular}

${ }^{*} p<.05 .{ }^{* *} p<.001$ (2-tailed).

descriptive analysis shows that the MOH's website is perceived to be most credible $(M=21.17, S D=3.33)$, followed by the WHO $(M=20.71$, $S D=3.72)$, the $\mathrm{MOH}$ Twitter site $(M=20.63, S D=3.61)$, the CDC $(M=20.38, S D=3.89)$, and the $\mathrm{MOH}$ YouTube channel $(M=20.14$, $S D=3.78)$.

\section{Research Question 2}

Kruskal-Wallis, with questions that have three choices (yes, no, I don't know), and Mann-Whitney, with two choices (yes, no), were run to test the correlations between the HBM subscales and adherence to the preventive measures that the $\mathrm{MOH}$ has delivered and recommended.

Frequency of handwashing. Respondents were asked about the frequency of daily handwashing. The data for individuals' HBM subscales were analyzed using the Spearman correlation coefficient. The findings are summarized in Table 4.

The results show that perceived severity $(p<.05)$ and perceived barriers $(p<.001)$ are significantly related with the frequency of handwashing. Perceived barriers are negatively related with the frequency of handwashing. Thus respondents with higher perceived barriers are less likely to wash their hands than those with lower perceived barriers. The results also show a positive relationship between perceived severity and the frequency of handwashing. Respondents with higher perceived severity scores are more likely to wash their hands than those with lower scores. The relationship between perceived susceptibility and benefits and the frequency of handwashing was not significant.

Wearing masks when visiting sick people. Respondents who said 
they visited sick people were asked if they wore a mask. The nonparametric Kruskal-Wallis test indicates that the perceived susceptibility, $\chi^{2}(2, N=552)=8.443, p<.001$, perceived severity, $\chi^{2}(2, N=552)=6.982$, $p<.05$, perceived benefits, $\chi^{2}(2, N=552)=30.445, p<.001$, and perceived barriers, $\chi^{2}(2, N=552)=42.996, p<.001$, have significant relationships with the preventive measure of wearing a mask when visiting sick people. The data show that people with higher susceptibility scores $(M d n=13)$ are more likely to adhere to this behavior than those with lower scores $(M d n=12)$. The results also show that respondents with higher benefits scores $(M d n=28)$ are more likely to wear a mask than those with lower scores $(M d n=26)$. However, respondents with high severity scores $(M d n=18)$ are less likely to wear a mask than those with lower scores $(M d n=16)$. Similarly, respondents with higher barriers scores $(M d n=18)$ are less likely to wear a mask when visiting sick people than respondents with lower barriers scores $(M d n=14)$.

Staying away from camels. Respondents were asked if they kept away from camels. The Mann-Whitney $U$-test indicated that perceived benefits, $U=7,747.5, p<.001$, and barriers, $U=9,565.0, Z=-3.322$, $p<.001$, have significant relationships with this preventive measure. Respondents with higher benefits scores $(M d n=27)$ are more likely to keep away from camels than those with lower scores $(M d n=25)$. Additionally, respondents with higher barriers scores $(M d n=20)$ are less likely to follow this preventive measure than those with lower scores $(M d n=16)$. Relationships between susceptibility and severity and staying away from camels were not significant.

Getting enough sleep. Participants were asked if they got enough sleep every day. Participants defined for themselves if they thought they were getting enough sleep and answered this question yes or no. The Mann-Whitney $U$-test was used to examine the association between each subscale of the HBM and the preventive MERS-CoV measure of getting enough sleep. The findings indicate significant relationships between perceived severity, $U=29,095.0, Z=-2.551, p<.05$, perceived benefits, $U=29,819.0, Z=-2.837, p<.05$, and perceived barriers, $U=28,597.5, p<.01$, and getting enough sleep. Respondent with high benefit scores $(M d n=27)$ are more likely to get enough sleep than respondents with lower scores $(M d n=26)$. In contrast, respondents with 
high barriers scores $(M d n=17)$ and severity scores $(M d n=19)$ are less likely to get enough sleep than those with lower scores $(M d n=16$ and $M d n=18$, respectively). No significant relationship was found between perceived susceptibility and this particular behavior.

Following a healthy and balanced diet. The Mann-Whitney $U$-test was used to examine the relationship between each subscale of the HBM and the preventive MERS-CoV measure of following a healthy and balanced diet. A significant relationship was found for the perceived severity, $U=33,935.0, Z=-1.960, p<.05$, and perceived barriers, $U=30,888.0, Z=-3.602, p<.001$. Respondents with higher severity scores $(M d n=18)$ were more likely to follow a healthy and balanced diet than those with lower scores $(M d n=17)$, whereas those with higher barriers scores were less likely to follow a healthy diet $(M d n=16)$. The relationship between susceptibility and a healthy and balanced diet is not significant.

\section{Covering the mouth or using a tissue when coughing or sneez-} ing. The Mann-Whitney $U$-test indicated that there is a significant relationship between perceived benefits and the preventive measure of covering the mouth or using a tissue when coughing or sneezing, $U=10,754.5, Z=-4.785, p<.001$. Respondents with high perceived benefits scores $(M d n=27)$ are more likely to cover their mouths when sneezing than those with lower scores $(M d n=25)$. The Mann-Whitney $U$-test also showed a relationship between perceived barriers and the preventive measure of covering the mouth when sneezing, $U=11,727.0$, $Z=-3.993, p<.001$. Those with high barriers scores $(M d n=19)$ are less likely to cover their mouths when sneezing than respondents with lower barriers scores $(M d n=16)$. However, the Mann-Whitney $U$-test indicated that neither perceived susceptibility nor perceived severity is significantly related with covering the mouth when sneezing or coughing.

Taking time to exercise weekly. The data for the individuals' HBM subscales were analyzed using the Spearman correlation coefficient. Results indicate significant relationships between perceived severity, $p<.01$, perceived benefits, $p<.01$, perceived barriers, $p<.01$, and the preventive measure of exercise. Perceived severity and perceived barriers were negatively correlated with time spent on exercise. In contrast, perceived benefits was positively correlated with time devoted to 
exercise every week. The relationship between perceived susceptibility, $p=.279$, and time spent on exercising was not significant.

\section{Research Question 3}

Frequency of handwashing. Respondents were asked about the frequency of daily handwashing. The data for the individuals' HBM subscales were analyzed using the Spearman correlation coefficient. The results show that cues to action, $p<.001, \rho=.190$, and self-efficacy, $p<.01, \rho=.145$, are positively correlated with the preventive measure of handwashing. Respondents with higher cues to action and selfefficacy scores are more likely to wash their hands than respondents with lower scores.

Wearing a mask when visiting sick people. Respondents who said they visited sick people were asked if they wore a mask. The nonparametric Kruskal-Wallis test indicated that cues to action, $\chi^{2}(2, N=552)=35.698, p<.001$, and self-efficacy, $\chi^{2}(2, N=552)=38.884$, $p<.001$, are significantly related to the preventive measure of wearing a mask when visiting sick people. The data show that people with higher cues to action scores $(M d n=36)$ are more likely to adhere to this behavior than those with lower scores $(M d n=32)$ or those who do not visit sick people $(M d n=33)$. The results also show that respondents with higher self-efficacy scores $(M d n=39)$ are more likely to wear a mask than those with lower scores $(M d n=35)$.

Staying away from camels. Respondents were asked if they kept away from camels. The Mann-Whitney $U$-test indicated that cues to action, $U=10,652.0, Z=-2.336, p<.05$, and self-efficacy, $U=7,620.0$, $Z=-5.088, p<.001$, are significantly related with this preventive measure. Respondents with higher cues to action scores $(M d n=33)$ are more likely to keep away from camels than those with lower scores $(M d n=32)$; however, respondents with higher self-efficacy scores $(M d n=36)$ are less likely to follow this preventive measure than those with lower scores $(M d n=33)$.

Getting enough sleep. Participants were asked if they get enough sleep every day. The Mann-Whitney $U$-test was used to examine the association between each subscale of the HBM and the preventive MERS-CoV measure of getting enough sleep. The study indicates 
significant relationships between cues to action, $U=26,772.0, Z=$ $-3.878, p<.001$, and self-efficacy, $U=28,106.0, Z=-3.117, p<.01$, and getting enough sleep. Respondents with high cues to action scores $(M d n=33)$ are more likely to get enough sleep than respondents with lower scores $(M d n=32)$. Respondents with high self-efficacy scores $(M d n=36)$ are more likely to get enough sleep than those with lower scores $(M d n=35)$.

Following a healthy and balanced diet. The Mann-Whitney $U$-test was used to examine the relationship between cues to action, selfefficacy, and the preventive MERS-CoV measure of following a healthy and balanced diet. A significant relationship was found for the perceived cues to action, $U=22,755.0, Z=-7.987, p<.001$, and self-efficacy, $U=28,228.0, Z=-5.036, p<.001$. Respondents with higher cues to action scores $(M d n=35)$ are more likely to follow healthy and balanced diets than those with lower scores $(M d n=31.5)$. Also, respondents with higher self-efficacy scores $(M d n=37)$ are more likely to follow healthy and balanced diets than respondents with lower scores $(M d n=36)$.

Covering the mouth or using a tissue when coughing or sneezing. The Mann-Whitney $U$-test indicated that there is a significant relationship between perceived cues to action and the preventive measure of covering the mouth or using a tissue when coughing or sneezing, $U=12,067.5, Z=-3.719, p<.001$. Respondents with high cues to action scores $(M d n=33)$ are more likely to cover their mouths when sneezing than those with lower scores $(M d n=30)$. The Mann-Whitney $U$-test also shows a positive correlation between self-efficacy and the preventive measure of covering the mouth when sneezing, $U=11,018.5$, $Z=-4.566, p<.001$. Those with higher self-efficacy scores $(M d n=36)$ are more likely to cover their mouths when sneezing than respondents with lower scores $(M d n=33)$.

Taking time to exercise weekly. The data for both cues to action and self-efficacy scales were analyzed using the Spearman correlation coefficient. The data show significant relationships between cues to action, $p<.001, \rho=.240$, and the time devoted to exercising every week. The data also show that self-efficacy, $p<.01, \rho=.122$, also is positively correlated with time devoted to exercising every week. 


\section{Discussion}

\section{$\mathrm{MOH}$ as a Credible Source}

The results show that the $\mathrm{MOH}$ website and social media are likely places for Saudi people to seek information on MERS-CoV, after Internet searches. Physicians ranked third. Interestingly, although physicians ranked third for seeking information, they ranked sixth as most credible source. The MOH website ranked first as the most credible source for MERS-CoV information, followed by the WHO, the MOH's Twitter page, the CDC, the MOH's YouTube channel, and doctors and health care providers. This finding is compatible with the report recently released by the Saudi online newspaper Makkah, which stated that the MERS-CoV topic was among the most searched on the MOH's website (“Seasonal Influenza," 2017). This may indicate that the $\mathrm{MOH}$ was able to regain trust when it implemented strategic communication during the "We Can Stop It" campaign, thus showing high Web traffic from users searching for MERS-CoV information.

Although these findings indicate that the $\mathrm{MOH}$ is seen as a credible source, five credibility measures were applied to better understand if there are differences in believability, accuracy, trustworthiness, being unbiased, and completeness among the 16 communication channels. The $\mathrm{MOH}$ website and $\mathrm{MOH}$ Twitter account ranked first and second, respectively, for most believable, accurate, and trustworthy. The $\mathrm{MOH}$ website also ranked first for most complete information on MERS-CoV.

\section{Perceived Susceptibility and Severity}

Only one preventive measure was significantly related to susceptibility. Those who perceived a higher risk of contracting MERS-CoV were more likely to wear a mask and see the benefit of doing so. As part of the campaign, posters depicted people wearing a mask when visiting sick people, thus indicating that this guideline was being followed.

The severity of contracting the virus is positively correlated with handwashing and eating a healthy and balanced diet, meaning the more people perceive they are at risk for contracting MERS-CoV, the more likely they are to wash their hands frequently and eat healthier. Surprisingly, wearing a mask, getting enough sleep, and getting enough 
exercise are negatively correlated. This means that although people perceive the severity of contracting MERS-CoV as being great, they have not been influenced to get more sleep or exercise, eat a healthier diet, or wear a mask when visiting sick people. Perhaps this disconnect is due to a mentality of believing that they will not get sick, or perhaps they have not yet encountered anyone with the virus. This warrants a second phase of this campaign, which should focus on susceptibility to the disease. Campaign messages based on Ajzen and Fishbein's (1980) theory of reasoned action could be useful in moving people toward practicing the MOH's recommended preventive behaviors (Ajzen, 2012).

\section{Perceived Benefits and Barriers}

Five preventive measures were associated with benefits of practicing the behaviors. These were wearing a mask when visiting sick people, staying away from camels, getting enough sleep, getting enough exercise, and covering the mouth or using a tissue when coughing or sneezing. Key campaign messages providing step-by-step guidance through verbal and visual methods may have contributed to these healthy practices. Interestingly, the practices of frequent handwashing and eating a healthy and balanced diet were not significant.

Not surprisingly, if barriers to practicing these recommendations are high, people are less likely to practice them. This is the case for washing hands frequently, staying away from camels, getting enough sleep and exercise, eating a healthy and balanced diet, and covering the mouth or using a tissue when coughing or sneezing. Several explanations can be offered here. For camel herders, it is not possible to stay away from camels - their livelihood. If people are working long hours at a job and/or tending to family needs, sleep and exercise may suffer. If people do not have access to a tissue, they may cough or sneeze into their hands, which is an unsanitary practice. Decreasing barriers to practice is probably the greatest challenge this campaign faces, as many situations, such as being a camel herder or being a working parent, cannot be changed. At the same time, campaign messages should continue to remind people to practice these healthy behaviors when possible.

Interestingly, wearing a mask when visiting sick people is seen 
as a barrier, yet people are also more likely to practice this behavior. This is the only barrier that respondents say they are willing or able to overcome, meaning practicing this behavior is important to them in preventing the spread of MERS-CoV.

\section{Cues to Action and Self-Efficacy}

Respondents with higher cues to action, both external and internal, are more likely to perform all of the recommended preventive guidelines than those with lower scores. These included washing hands frequently, staying away from camels, getting enough sleep, getting enough exercise, eating a healthy and balanced diet, and covering the mouth or using a tissue when coughing or sneezing.

External cues are those factors that trigger people to change their behavior and may include events, people, mass media, and health providers, among other factors. Internal cues include psychological cues, such as pain and symptoms that trigger individuals to adopt a new behavior. It is reasonable to argue that, to some extent, the external cues the "We Can Stop It" campaign provided contributed to the practice of the behaviors. It is also reasonable to argue that many health providers adopted the $\mathrm{MOH}$ guidelines and that use of traditional and social media helped moved the campaign messages into the public sphere.

Self-efficacy was positively correlated with five of the six recommended preventive guidelines; that is, Saudi people are more likely to wash their hands frequently, get enough sleep, get enough exercise, eat a healthy and balanced diet, and cover the mouth or use a tissue when coughing or sneezing if they have higher levels of self-efficacy. The campaign messages teach people how to perform a new behavior and stress that they have the ability and capability to make change. The more people believe in their ability and skill to achieve a certain goal, the more likely they will be to attain that goal. Key campaign messages may have contributed to providing the self-efficacy people needed to perform these behaviors.

Self-efficacy was negatively correlated with staying away from camels. This makes sense in that those who work with or around camels would not have the ability to stay away from them. 


\section{Overall Impact}

In the "We Can Stop It" campaign, two-way communication replaced the MOH's one-way model of communicating during the megacrisis of the initial MERS-CoV outbreak. Although no benchmark study is available with which to assess credibility levels of the $\mathrm{MOH}$ at the beginning of the crisis, media coverage, public outrage on social media, and the firing of the minister of health all pointed to failures to communicate effectively. Since launching the "We Can Stop It" campaign, the $\mathrm{MOH}$ has become the first place Saudis go to seek information on MERS-CoV, after Internet search engines. This is consistent with Fox and Duggan's (2013) study that found that the majority of Internet users in the United States go first to the Internet search engines, such as Google and Yahoo!, to seek health information. Ranking the $\mathrm{MOH}$ as the first place to seek MERS-CoV information after the Internet search engines also is consistent with crisis communication guidelines in which an organization should position itself as the main source of information to tell its side of the story during a crisis (Coombs, 2014). Being the main source of information during a crisis ensures that an organization will be in charge of handling the flow of accurate information (Coombs, 2007). The MOH, in fact, declares its website to be the main hub for MERS-CoV information. Furthermore, the study found that the MOH's website is seen as the most credible source of information among 15 other communication channels, including international organizations. This success could partially be attributed to the implementation of a strategic communication plan and effective policy that emphasizes transparency, accountability, accuracy, and engagement with the public, as seen in the "We Can Stop It" campaign.

The study also found that the majority of participants are more likely to use social media to seek information about MERS-CoV than traditional media. This is consistent with the Pew Research (2016) findings that traditional media in the United States are witnessing a dramatic decrease in use among younger generations, especially newspapers. Those aged between 18 and 29 years, the primary demographic of this study, depend less on traditional media for information than any other age group. This age group is more likely to use digital media, apps, and social networking sites to seek information, according to the Pew 
research report. The emphasis on social media, especially Twitter, has allowed the public to be more interactive with the $\mathrm{MOH}$. For example, the $\mathrm{MOH}$ tweets weekly updates on new cases and provides specific tips on how to avoid the virus. People are then encouraged to retweet these health messages, providing others with consistent, accurate, and timely updates. With approximately 8.5 million followers, the MOH Twitter site has proven to be an effective two-way communication tool. What has shown to be the least effective of MOH's communication tools is its Facebook page, which ranked lowest of all the MOH's communication channels. Facebook, in general, ranked low on all measures of credibility, indicating that Facebook is not the strongest or best method to reach Saudi people with pertinent health information.

Regarding campaign messages, participants who had high scores on the HBM five dimensions (susceptibility, severity, benefits, cues to action, and self-efficacy) were more likely to comply with the MOH's guidelines and instructions. For instance, people with higher selfefficacy, cues to action, and perceived severity were more likely to wash their hands than those with lower scores. Respondents with high HBM scores were more likely to wear a mask when visiting sick people. Such findings are consistent with Champion's (1990) correlations between high HBM scores and the frequency of breast self-examination.

The study also found that respondents with high barriers scores are less likely to follow the MOH's MERS-CoV preventive measures, hence the importance of reducing these barriers by addressing the challenges and obstacles that prevent Saudis from performing the MOH's recommended behaviors. Further studies could help the MOH better understand what people need to overcome the barriers and then provide effective communication strategies to address these needs.

The study showed that Saudis have the self-efficacy to follow the campaign's recommendations, except for staying away from camels. This shows the importance of campaigns providing the necessary tools to change a behavior.

\section{Limitations}

This study had three limitations. The first was the use of a convenience sample. Although a convenience sample is less expensive than other 
types of sampling, it can provide useful information for researchers in a short period of time (Wimmer \& Dominick, 2011). Cost was the prohibitive factor in gaining a sample from the larger population. The second limitation was the use of college students as the unit of analysis. It is worth noting, however, that KSU is located in Riyadh, the city with the largest number of MERS-CoV cases. It is the largest university in the country and hosts both domestic students from various regions and international students. Third, nonresponse bias was another limitation of this study. Although the e-mail invitation to participate in this study was sent to all KSU students, only 875 participated in the study, leaving a large number of KSU students who might carry different perspectives about the topic under study. Fourth, the study did not include baseline data or a control group to assess the credibility of the MOH's MERS-CoV messages; rather, it relied on participant self-report after the MERS-CoV crisis.

Finally, we recognize that people may have been practicing preventive behaviors before the campaign or are practicing them without having been exposed to the campaign; however, we assert that the MOH's strong credibility has positively influenced attitudes and behaviors in following preventive recommendations.

\section{Conclusion}

The results from this study indicate that the $\mathrm{MOH}$ has gained credibility since hiring a new minister of health and launching the "We Can Stop It" campaign. The results further illustrate that the campaign is having a positive impact in that the majority of participants are practicing most, but not all, of the preventive guidelines set forth in the campaign. Campaign planners facing megacrises can learn from this study how best to develop effective campaigns. The first step is to be sure that the organization's key constituents see it as credible. The second step is to provide a strong theoretical framework from which to develop the campaign. Finally, campaigns that address perceived susceptibility and severity of contracting a deadly virus and that identify perceived benefits of and barriers to practicing recommended preventive health guidelines are more likely to be successful. 
Saud A. Alsulaiman is a PhD student in the School of Media and Communication at Bowling Green State University, where he studies public relations, health communication, social media, and crisis management. Saud specializes in strategic health communication, particularly emergency public health and risk communication efficacy.

Terry L. Rentner, PhD, is professor at Bowling Green State University, where she teaches public relations and journalism courses at the undergraduate level and pedagogy, public relations theory and practice, advertising theory and practice, and health communication campaigns at the graduate level. Her research focuses on high-risk drinking, tobacco use, prescription drug misuse, suicide prevention, and international health campaigns.

\section{ORCID}

Saud A. Alsulaiman (10 https://orcid.org/oooo-0oo2-2164-4396

\section{References}

Abolfotouh, M. A., Ala’a, A. B., Mahfouz, A. A., Al-Assiri, M. H., Al-Juhani, A. F., \& Alaskar, A. S. (2015). Using the health belief model to predict breast self examination among Saudi women. BMC Public Health, 15(1), 1163. https://doi.org/10.1186/s12889-015-2510-y

Adams, A., Hall, M., \& Fulghum, J. (2014). Utilizing the health belief model to assess vaccine acceptance of patients on hemodialysis. Nephrology Nursing Journal, 41, 393-407. Retreived from https://www.ncbi.nlm.nih .gov/pubmed/25244894

Ajzen, I. (2012). Martin Fishbein's legacy: The reasoned action approach. Annals of the American Academy of Political and Social Science, 640(1), 11-27. https://doi.org/10.1177/0oo2716211423363

Ajzen, I., \& Fishbein, M. (1980). Understanding attitudes and predicting social behavior. Englewood Cliffs, NJ: Prentice Hall.

Almadi, M. A., Mosli, M. H., Bohlega, M. S., Al Essa, M. A., AlDohan, M. S., Alabdallatif, T. A., \& Mandil, A. (2015). Effect of public knowledge, attitudes, and behavior on willingness to undergo colorectal cancer screening 
using the health belief model. Saudi Journal of Gastroenterology, 21, 71-77. https://doi.org/10.4103/1319-3767.153814

Alomran, A., Knickmeyer, B., \& McKay, E. (2014, April 21). Saudi health minister fired amid surge in deadly MERS virus: Official said there was no medical reason for stricter measures to control the disease. Wall Street Journal. Retrieved from http://www.wsj.com/articles/SB10001424052702304049 904579516032023791644

British Broadcasting Corporation. (2014, May 12). Saudi fears rise over mystery virus. Retrieved from http://www.bbc.com/news/world-middle -east-27337627

Cao, Z.-J., Chen, Y., \& Wang, S.-M. (2014). Health belief model based evaluation of school health education programme for injury prevention among high school students in the community context. BMC Public Health, 14(1), 1-15. https://doi.org/10.1186/1471-2458-14-26

Centers for Disease Control and Prevention. (2015). Middle East Respiratory Syndrome (MERS). Retrieved from http://www.cdc.gov/coronavirus/mers /index.html

Centers for Disease Control and Prevention. (2017). MERS in the Arabian Peninsula. Retrieved from https://wwwnc.cdc.gov/travel/notices/alert /coronavirus-saudi-arabia-qatar

Champion, V. L. (1990). Breast self-examination in women 35 and older: A prospective study. Journal of Behavioral Medicine, 13, 523-538. https://doi .org/10.1007/BFoo844733

Champion, V. L. (1993). Instrument refinement for breast cancer screening behaviors. Nursing Research, 42, 139-143. Retrieved from https://www.ncbi .nlm.nih.gov/pubmed/8506161

Champion, V. L., \& Skinner, C. S. (2008). The health belief model. In K. Glanz, B. K. Rimer, \& K. Viswanath (Eds.), Health behavior and health education: Theory, research, and practice (4th ed., pp. 45-65). San Francisco: Jossey-Bass.

Coombs, W. T. (2007). Crisis management and communications. Retrieved from http://www.instituteforpr.org/topics/crisis-management-and-com munications/

Coombs, W. T. (2014). Crisis management and communications. Research Journal of the Institute for Public Relations, 1(1). Retrieved from http:// www.instituteforpr.org/crisis-management-communications/ 
Fox, S., \& Duggan, M. (2013). Information triage. Retrieved form http://www .pewinternet.org/2013/01/15/information-triage/

Glanz, K., Rimer, B. K., \& Lewis, F. M. (2002). Health behavior and health education: Theory, research, and practice. San Francisco, CA: Jossey-Bass.

Hayden, J. (2013). Introduction to health behavior theory (2nd ed.). Burlington, MA: Jones \& Bartlet.

Hochbaum, G. M. (1958). Public participation in medical screening programs: A socio-psychological study. Washington, DC: U.S. Department of Health, Education, and Welfare, Public Health Service, Bureau of State Services, Division of Special Health Services, Tuberculosis Program.

Hochbaum, G., Rosenstock, I., \& Kegels, S. (2016). Health belief model. Washington, DC: U.S. Public Health Service. (Original work published 1952)

Hoseini, H., Maleki, F., Moeini, M., \& Sharifirad, G. R. (2014). Investigating the effect of an education plan based on the health belief model on the physical activity of women who are at risk for hypertension. Iranian Journal of Nursing \& Midwifery Research, 19, 647-652. Retrieved from https://www .ncbi.nlm.nih.gov/pmc/articles/PMC4280731/

Janz, N. K., \& Becker, M. H. (1984). The health belief model: A decade later. Health Education \& Behavior, 11, 1-47. https://doi.org/10.1177/1090198 18401100101

Meyer, P. (1988). Defining and measuring credibility of newspapers: Developing an index. Journalism \& Mass Communication Quarterly, 65, 567-574. https://doi.org/10.1177/107769908806500301

Mikhail, B. I., \& Petro-Nustas, W. I. (2001). Transcultural adaptation of Champion's health belief model scales. Journal of Nursing Scholarship, 33, 159-165. Retrieved from https://www.ncbi.nlm.nih.gov/pubmed/11419312

Ministry of Health of the Kingdom of Saudi Arabia. (2015). Coronavirus (MERS-Cov). Retrieved from http://www.moh.gov.sa/en/Ministry/Media Center/News/Pages/News-2015-03-04-002.aspx

Ministry of Health of the Kingdom of Saudi Arabia. (2017). Ways of protection against the coronaviris (MERS-Cov). Retrieved from http://www.moh.gov .sa/en/CCC/Pages/default.aspx

Naghashpour, M., Shakerinejad, G., Lourizadeh, M. R., Hajinajaf, S., \& Jarvandi, F. (2014). Nutrition education based on health belief model improves dietary calcium intake among female students of junior high schools. Journal of Health, Population \& Nutrition, 32, 420-429. Retrieved from https://www.ncbi.nlm.nih.gov/pmc/articles/PMC4221448/ 
National Cancer Institute. (2005). Theory at a glance: A guide for health promotion practice. Washington, DC: U.S. Department of Health and Human Services. Retrieved from https://cancercontrol.cancer.gov/brp/research /theories_project/theory.pdf

Pew Research Center. (2016). The modern news consumer: News attitudes and practices in the digital era. Retrieved from http://www.journalism .org/2016/07/07/the-modern-news-consumer/

Reuters. (2014, June 12). Insight-Saudi MERS response hobbled by institutional failing. Retrieved from http://www.reuters.com/article/2014/o6/12/saudi -mers-failings-idUSL5NoOR52 $\mathrm{G}_{20140612}$

Rosenstock, I. M., Strecher, V. J., \& Becker, M. H. (1988). Social learning theory and the health belief model. Health Education Quarterly, 15, 175-183. https:// doi.org/10.1177/109019818801500203

Seasonal influenza, coronavirus, and medical referrals are the most searched topics in the Ministry of Health's website. (2017, March 30). Makkah. Retrieved from http://makkahnewspaper.com/article/598280

Thweatt, T., \& Query, J. (2005). Health belief model. In R. Heath (Ed.), Encyclopedia of public relations (pp. 383-386). Thousand Oaks, CA: Sage. https://doi.org/10.4135/9781412952545.n193

West, M. D. (1994). Validating a scale for the measurement of credibility: A covariance structure modeling approach. Journalism Quarterly, 71, 159-168. https://doi.org/10.1177/107769909407100115

Wimmer, R., \& Dominick, J. (2011). Mass media research: An introduction (9th ed.). Boston, MA: Wadsworth.

World Health Organization. (2015). Frequently asked questions on Middle East respiratory syndrome coronavirus (MERS-CoV). Retrieved from http:// www.who.int/csr/disease/coronavirus_infections/faq/en/

World Health Organization. (2016). Surveillance, forecasting and response. Retrieved from http://www.emro.who.int/surveillance-forecasting-response /surveillance-news/mers-mission-january2016.html

Yen, Y., \& Salmon, C. T. (2017). Further explication of mega-crisis concept and feasible responses. Retrieved from https://www.shsconferences.org/articles /shsconf/abs/2017/01/shsconf_icome2017_0oo34/shsconf_icome2017_0o 034.html 